\title{
HUBUNGAN DUKUNGAN KELUARGA DENGAN PEMANFAATAN POS PELAYANAN TERPADU LANJUT USIA MELATI PUTIH WILAYAH KERJA PUSKESMAS PALARAN KOTA SAMARINDA TAHUN 2018
}

\author{
Rindha Mareta Kusumawati ${ }^{1}$, Nolla Indra Susanti ${ }^{2}$ \\ rindhamaretakusumawati@gmail.com ${ }^{1}$, nollaindrasusanti21@gmail.com² \\ Universitas Widya Gama Mahakam
}

\begin{abstract}
ABSTRAK
Posyandu Lansia Melati Putih merupakan salah satu posyandu lansia yang ada di wilayah kerja Puskesmas Palaran, dimana jumlah kunjungan mengalami penurunan. Tujuan penelitian ini untuk mengetahui hubungan dukungan keluarga dengan pemanfaatan Pos Pelayanan Terpadu Lanjut Usia Melati Putih wilayah kerja Puskesmas Palaran. Jenis penelitian kuantitatif menggunakan metode survey analitik dengan pendekatan cross sectional. Sampel dalam penelitian ini adalah lansia yang terdaftar sebagai anggota Posyandu Lansia Melati Putih wilayah kerja Pusat Kesehatan Masyarakat Palaran Kota Samarinda berjumlah 46 orang. Analisis data menggunakan uji chi square. Hasil penelitian menunjukkan bahwa ada hubungan dukungan keluarga (hasil $p$ value : 0,003 $<\alpha: 0,05)$ dengan pemanfaatan Pos Pelayanan Terpadu Lanjut Usia Melati Putih wilayah kerja Puskesmas Palaran Kota Samarinda.
\end{abstract}

Kata Kunci : Dukungan Keluarga, Pemanfaatan Pos Pelayanan Terpadu, Lansia

\begin{abstract}
Melati Putih Elderly Integrated Service Posts is one of the Elderly Integrated Service Posts in work area Palaran Community Health Center, where the number of visits has decreased. The purpose of this study was to determine family support by utilizing of Melati Putih Elderly Integrated Service Posts The working area of the Palaran Community Health Center.This type of quantitative research uses analytical survey method with cross sectional approach. The sample in this study were elderly who were registered as members of the of Melati Putih Elderly Integrated Service Posts The working area of the Palaran Community Health Center was 46 people. Data analysis used chi square test.The results show that is a family support relationship (the result of $p$ value: $0.003<\alpha: 0.05$ ) by utilizing the Melati Putih Elderly Integrated Service Post working area of the Palaran Community Health Center in Kota Samarinda.
\end{abstract}

Keywords: Family Support, Utilization of Integrated Service Posts, Eldery 


\section{PENDAHULUAN}

\section{A. Latar Belakang}

Pos Pelayanan Terpadu Lanjut Usia (selanjutnya disingkat Posyandu Lansia) merupakan wadah pelayanan kesehatan bersumber daya masyarakat untuk melayani penduduk lansia, dengan tujuan mengupayakan lansia menikmati masa tua bahagia dan berguna, promotif dan preventif, pembinaan pelayanan kesehatan, gizi dan psikososial agar kondisi kesehatan lansia terjaga sehingga tetap produktif.

Indonesia termasuk lima besar negara dengan jumlah penduduk lansia terbanyak di dunia. Menurut BPS Provinsi Kalimantan Timur (2014) jumlah lansia tiga tahun terakhir mengalami peningkatan yaitu tahun 2012 sebesar 149.697 jiwa $(4,03 \%)$ dari 3.714 .560 jiwa, tahun 2013 menjadi 196.483 jiwa $(5,17 \%)$ dari 3.800 .451 jiwa dan tahun 2014 menjadi 265.236 jiwa $(6,82 \%)$ dari 3.889 .085 jiwa. Kota Samarinda yang merupakan ibukota dari Provinsi Kalimantan Timur juga mengalami peningkatan jumlah lansia tiga tahun terakhir yaitu tahun 2015 terdapat 34.112 jiwa $(4,6 \%)$ dari 741.554 jiwa, tahun 2016 menjadi 39.715 jiwa $(5,3 \%)$ dari 749.340 jiwa dan tahun 2017 menjadi 46.947 jiwa $(6,2 \%)$ dari 757.208 jiwa. Akan tetapi jumlah lansia dibina mengalami penurunan yaitu tahun 2015 sebesar 30\%, tahun 2016 menjadi 28\% dan tahun 2017 hanya mencapai 25\% (Dinas Kesehatan Kota Samarinda, 2017).

Di Kecamatan Palaran, jumlah lansia tahun 2015 yaitu 1.478 jiwa lansia $(12,1 \%)$ dari 17.835 jiwa, tahun 2016 yaitu 1.635 jiwa $(11,8 \%)$ dari 19.230 jiwa dan tahun 2017 yaitu 1.832 jiwa $(11,8 \%)$ dari 21.550 jiwa. Di Kecamatan Palaran terdapat Puskesmas Palaran, Puskesmas Bantuas dan Puskesmas Bukuan (Profil Kecamatan Sambutan, 2014).

Data jumlah kunjungan lansia ke posyandu lansia dari masing-masing wilayah kerja Puskesmas Kecamatan Palaran, terbanyak Posyandu di wilayah kerja Puskesmas Bantuas dengan kunjungan rata-rata per bulan 69 orang (80,2\%), Posyandu Lansia di wilayah kerja Puskesmas Bukuan menempati urutan kedua dengan kunjungan rata-rata per bulan paling sedikit yaitu 62 orang $(72,1 \%)$ dan Posyandu Lansia di wilayah kerja Puskesmas Palaran menempati urutan ketiga dengan kunjungan rata-rata per bulan 32 orang (37,2\%). Berdasarkan data tersebut, posyandu lansia di wilayah kerja Puskesmas Palaran paling rendah dibandingkan posyandu lansia di wilayah kerja lainnya.

Posyandu Lansia Melati Putih merupakan salah satu posyandu lansia yang ada di wilayah kerja Puskesmas Palaran diketahui dari segi ketersediaan layanan Posyandu Lansia Melati Putih dalam pelaksanaan kegiatannya menempai Balai Desa berupa ruang terbuka dan tidak terdapat plang nama Posyandu Lansia Melati Putih ditempat tersebut. Dilihat dari kader yang aktif terdapat 9 orang dengan jumlah anggota yang aktif yaitu 60 orang dari 86 anggota yang terdaftar. Adapun jumlah kunjungan lansia tiga bulan terakhir yaitu bulan Mei 2018 sebanyak 28 orang dengan petugas kesehatan yang datang 5 orang, bulan Juni 2018 sebanyak 44 orang dengan petugas kesehatan yang datang 4 orang, dan bulan Juli 2018 sebanyak 35 orang dengan petugas kesehatan yang datang 6 orang. Oleh karena itu, jumlah kunjungan Posyandu Lansia Melati Putih mengalami penurunan dan yang hadir cukup rendah berkisar $40,7 \%$ dari jumlah anggota, padahal petugas kesehatan yang datang cukup banyak dan jumlah kader juga banyak yang datang.

Pemanfaatan Posyandu Lansia Melati Putih ini dapat dipengaruhi berbagai macam faktor, dimana menurut Bloom dalam (2012) perilaku manusia terdapat tiga domain sesuai dengan tujuan pendidikan yaitu kognitif (pengetahuan), afektif (sikap) dan psikomotor (dukungan keluarga). Dukungan keluarga dapat menjadi salah satu penyebab lansia tidak memanfaatkan Posyandu Lansia dengan optimal. 
Berdasarkan data tersebut, maka peneliti tertarik untuk melakukan penelitian mengenai "Hubungan Dukungan Keluarga Dengan Pemanfaatan Pos Pelayanan Terpadu Lanjut Usia Melati Putih Wilayah kerja Puskesmas Palaran Tahun 2018”.

\section{B. Rumusan Masalah}

Dari uraian tersebut maka rumusan masalah yang diangkat adalah : apakah ada hubungan pengetahuan, sikap dan dukungan keluarga dengan pemanfaatan Pos Pelayanan Terpadu Lanjut Usia Melati Putih wilayah kerja Pusat Kesehatan Masyarakat Palaran Kota Samarinda tahun 2018?

\section{Metode Penelitian}

Berdasarkan permasalahan dan tujuan yang hendak dicapai, maka metode penelitian ini adalah kuantitatif dengan jenis survei analitik yaitu penelitian yang bertujuan untuk mengungkapkan hubungan korelatif antara variabel independen dan variabel dependen, dengan menggunakan pendekatan cross sectional. Penelitian dilakukan di wilayah Posyandu Lansia Melati Putih pada bulan September 2018. Populasi dalam penelitian ini adalah seluruh lansia yang terdaftar sebagai anggota Posyandu Lansia Melati Putih wilayah kerja Puskesmas Palaran Kota Samarinda yang berjumlah 86 lansia. Sampel dalam penelitian ini adalah lansia yang terdaftar sebagai anggota Posyandu Lansia Melati Putih wilayah kerja Pusat Kesehatan Masyarakat Palaran Kota Samarinda berjumlah 46 orang. Teknik sampling yang digunakan dalam penelitian ini adalah nonprobability sampling dengan metode purposive sampling. Data yang telah dikumpulkan melalui kuesioner akan diolah menjadi dua macam teknik analisis data, yaitu analisis univariat dan analisis bivariate menggunakan Chi-Square.

\section{HASIL DAN PEMBAHASAN}

1. Analisis Univariat

Tabel 1. Distribusi Dukungan Keluarga Lansia wilayah kerja Puskesmas Palaran Kota Samarinda Tahun 2018

\begin{tabular}{ccc}
\hline $\begin{array}{c}\text { Dukungan } \\
\text { Keluarga }\end{array}$ & Jumlah & $(\boldsymbol{\%})$ \\
\hline Baik & 17 & 37 \\
Kurang Baik & 29 & 63 \\
\hline Total & $\mathbf{4 6}$ & $\mathbf{1 0 0}$ \\
\hline Sumber Data $:$ Data Primer Tahun 2018
\end{tabular}

Berdasarkan tabel 1 diperoleh gambaran bahwa dari 46 responden yang terlibat dalam penelitian ini sebagian besar dukungan keluarga kurang berjumlah 29 responden (63\%), sedangkan baik berjumlah 17 responden $(37 \%)$.

\section{Analisis Bivariat}

Tabel 2. Hubungan dukungan keluarga dengan pemanfaatan Pos Pelayanan Terpadu Lanjut Usia Melati Putih wilayah kerja Pusat Kesehatan Masyarakat Palaran Kota Samarinda

\begin{tabular}{|c|c|c|c|c|}
\hline$\underset{\text { gukun }}{\text { Dan }}$ & $\begin{array}{r}\text { Pemanfaat } \\
\text { La }\end{array}$ & $\begin{array}{l}\text { Posyandu } \\
\text { ia }\end{array}$ & & $p$ \\
\hline $\begin{array}{c}\text { Keluar } \\
\text { ga }\end{array}$ & $\begin{array}{c}\text { Memanfa } \\
\text { atkan }\end{array}$ & $\begin{array}{c}\text { Tidak } \\
\text { Memanfa } \\
\text { atkan }\end{array}$ & $\begin{array}{c}\text { Tot } \\
\text { al }\end{array}$ & val \\
\hline Baik & $\begin{array}{c}15 \\
32,6 \%\end{array}$ & $\begin{array}{c}2 \\
4,3 \%\end{array}$ & $\begin{array}{l}17 \\
37 \\
\%\end{array}$ & \\
\hline $\begin{array}{c}\text { Kurang } \\
\text { Baik }\end{array}$ & $\begin{array}{c}11 \\
23,9 \%\end{array}$ & $\begin{array}{c}18 \\
39,1 \%\end{array}$ & $\begin{array}{l}29 \\
63 \\
\% \\
\end{array}$ & $\begin{array}{l}0,0 \\
03\end{array}$ \\
\hline Total & $\begin{array}{c}26 \\
56,5 \%\end{array}$ & $\begin{array}{c}20 \\
43,5 \%\end{array}$ & $\begin{array}{c}46 \\
100 \\
\% \\
\end{array}$ & \\
\hline
\end{tabular}

Berdasarkan tabel 2 tersebut terlihat dari 17 responden memiliki dukungan keluarga baik, proporsi tertinggi pada lansia yang 
memanfaatkan posyandu lansia dengan hadir $\geq$ 6 kali berjumlah 15 responden $(32,6 \%)$, terdapat responden memiliki dukungan keluarga baik terhadap posyandu lansia namun tidak memanfaatkan posyandu lansia dengan hadir $<6$ kali berjumlah 2 responden $(4,3 \%)$. Adapun dari 29 responden memiliki dukungan keluarga kurang, proporsi tertinggi pada lansia yang tidak memanfaatkan posyandu lansia dengan hadir $<6$ kali berjumlah 18 responden $(39,1 \%)$, terdapat responden memiliki dukungan keluarga kurang namun memanfaatkan posyandu lansia dengan hadir $\geq$ 6 kali berjumlah 11 responden $(23,9 \%)$.

Hasil uji statistik dengan menggunakan chi kuadrat diperoleh hasil $p$ value : $0,003<\alpha$ : $0,05)$ sehingga $\mathrm{H}_{0}$ ditolak yaitu ada hubungan dukungan keluarga dengan pemanfaatan Pos Pelayanan Terpadu Lanjut Usia Melati Putih wilayah kerja Puskesmas Palaran Kota Samarinda. Ada hubungannya antara dukungan keluarga dengan pemanfaatan Pos Pelayanan Terpadu Lanjut Usia Melati Putih wilayah kerja Puskesmas Palaran Kota Samarinda, dikarenakan keluarga yang tidak mendukung lansia untuk pergi ke posyandu lansia cenderung membuat lansia tidak memanfaatkan atau tidak pergi ke posyandu lansia.

Menurut Suprajitno (2004) dukungan keluarga adalah bantuan yang bermanfaat secara emosional dan memberikan pengaruh positif yang berupa informasi, bantuan instrumental, emosi, maupun penilaian yang diberikan oleh anggota keluarga yangterdiri dari suami, orang tua, mertua, maupun saudara lainnya.

Hasil penelitian ini sejalan dengan penelitian Pertiwi (2008) yang menunjukkan bahwa terdapat hubungan antara dukungan keluarga denganfrekuensi kehadiran lanjut usia di Posyandu Lansia Desa Mudal Kabupaten Boyolali.

Berdasarkan hal tersebut, dapat diketahui bahwa dukungan keluarga memiliki peranan paling penting dalam pengambilan keputusan. Lansia akan tidak memanfaatkan
Posyandu lansia apabila keluarga khususnya anak kurang memberikan dukungan terhadap orang tua (lansia) dalam memanfaatkan posyandu lansia dalam bentuk memberikan informasi pentingnya posyandu lansia, memberitahu jadwal pelaksanaan posyandu lansia, memberikan biaya dan mengantarkan lansia pergi ke tempat pelayanan kesehatan atau posyandu lansia untuk memanfaatkan posyandu lansia.

Dukungan keluarga pada penelitian ini sudah sampai pada tahap melakukan pembicaraan terarah, menghormati dan menghargai, bersikap sabar dan bijaksana terhadap perilaku lansia, memberikan kasih sayang, menyediakan waktu, perhatian, memberi dorongan untuk tetap mengikuti kegiatan-kegiatan, memberi dorongan untuk tetap hidup bersih dan sehat dan memberi perhatian yang baik terhadap orang tua.

Dari hasil temuan tersebut di atas ternyata dukungan keluarga memegang peranan sangat penting. Oleh karena itu, keluarga harus bisa meluangkan waktu untuk menemani lansia bertukar pikiran atau mendengarkan keluh kisah lansia, sehingga lansia merasa diperhatikan dan bersemangat untuk hidup sehat serta tidak merasa menjadi beban.

\section{SIMPULAN}

Ada hubungan dukungan keluarga dengan pemanfaatan Pos Pelayanan Terpadu Lanjut Usia Melati Putih wilayah kerja Puskesmas Palaran Kota Samarinda (hasil $p$ value : 0,003 $<\alpha: 0,05)$.

\section{DAFTAR PUSTAKA Buku/Literatur:}

Ashri, Budi Astuti. 2015. Faktor-Faktor Yang Berhubungan Dengan Pemanfaatan Posyandu Lansia Al Hidayah Kelurahan Sambutan Kota 
Samarinda. Jurnal Kesehatan Masyarakat.

Azwar, S. 2013. Sikap Manusia Teori dan Pengukurannya. Penerbit Pustaka Pelajar. Yogyakarta.

BPS Provinsi Kalimantan Timur. 2014. Jumlah Lansia Provinsi Kalimantan Timur. Provinsi Kalimantan Timur.

Dahlan, S. 2014. Langkah-Langkah Membuat Proposal Penelitian Bidang Kedokteran dan Kesehatan. Penerbit Sagung Seto. Jakarta.

Depkes RI. 2013. Pedoman Pelaksanaan Promosi Kesehatan Di Puskesmas. Bina Kesehatan Masyarakat. Jakarta.

Depkes RI. 2015. Pedoman Pembinaan Kesehatan Usia Lanjut Bagi Petugas Kesehatan. Bina Kesehatan Masyarakat. Jakarta.

Dinas Kesehatan Kota Samarinda. 2017. Jumlah Lansia Kota Samarinda. Kota Samarinda.

Hana, Maulida Muflikhah. 2016. FaktorFaktor yang Berhubungan dengan Pemanfaatan Pelayanan Posyandu Lansia Di Kelurahan Bulusan Kecamatan Tembalang Kota Semarang. Jurnal Kesehatan Masyarakat.

Koentjoro. 2017. Metode Penelitian Kesehatan Edisi Pertama. Jakarta : Kencana.

Moleong. 2014. Metodologi Penelitian Kualitatif. Penerbit Remaja Rosdakarya. Bandung.

Noor, Juliansyah. 2015. Metodologi Penelitian. Prenada Media. Jakarta.

Notoatmodjo, S. 2010. Promosi Kesehatan dan Ilmu Perilaku. PT Rineka Cipta. Jakarta.

Notoatmodjo, S. 2012. Promosi Kesehatan dan Perilaku Kesehatan. PT Rineka Cipta. Jakarta.

Nurvi, Susanti. 2011. Faktor-Faktor yang Berhubungan dengan Pemanfaatan Pelayanan Posyandu Lansia FaktorFaktor yang Berhubungan dengan
Pemanfaatan Pelayanan Posyandu Lansia. Jurnal Kesehatan Masyarakat.

Padila. 2013. Buku Ajar Keperawatan Gerontik. Nuha Medika. Yogyakarta. Rumengan, Debra. 2015. Faktor-Faktor yang Berhubungan dengan Pemanfaatan Pelayanan Kesehatan Pada Peserta BPJS Kesehatan di Puskesmas Paniki Bawah Kecamatan Mapanget Kota Manado. Jurnal Penelitian JIKMU Suplemen Volume 5 Nomor 1.

Subirman. 2013. Metode Penelitian Kualitatif. Rajawali Pers. Jakarta.

Tjiptono, F. 2015. Strategi Pemasaran. Edisi Kedua. Cetakan Kedua. ANDI. Yogyakarta.

Undang-Undang Republik Indonesia Nomor 36 Tahun 2009 tentang Kesehatan. 